\title{
Pd-Catalyzed One-Pot Borylation/Intramolecular Asymmetric Arylation on $\alpha$-Ketiminoamides: Innovative Approach to Chiral 3-Amino-2-oxindoles
}

\author{
Carolina S. Marques*a (iD) \\ Simon E. Lawrence ${ }^{b}$ (iD \\ Anthony ]. Burke*a,c (D) \\ a Centro de Química de Évora, University of Évora, Institute for \\ Research and Advanced Training, CLAV, Rua Romão Ramalho 59, \\ 7000 Évora, Portugal \\ carolsmarq@uevora.pt \\ ajb@dquim.uevora.pt \\ b School of Chemistry, Analytical and Biological Chemistry \\ Research Facility, Solid State Pharmaceutical Centre, \\ University College Cork, Cork, Ireland \\ c Department of Chemistry, School of Science and Technology, \\ University of Évora, CLAV, Rua Romão Ramalho 59, 7000 Évora, \\ Portugal
}

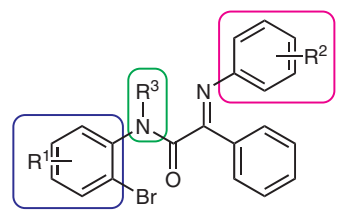

ortho-bromo- $\alpha$-ketimino amide derivatives
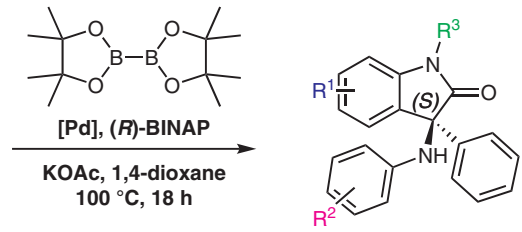

3-phenyl-3-(aryl-amino)-indolin-2-one derivatives 11 new compounds up to $98 \%$ yield up to $76 \%$ ee
Received: 30.08 .2017

Accepted after revision: 04.10.2017

Published online: 03.11 .2017

DOI: 10.1055/s-0036-1590940; Art ID: st-2017-d0656-

Abstract 3-Amino-2-oxindole derivatives are a common framework found in many natural products and medicinal compounds and thus their synthesis is of significant importance. We report for the first time a one-pot approach for the synthesis of these compounds, using a borylation/intramolecular asymmetric arylation sequence starting from ortho-bromo- $\alpha$-ketimino amide derivatives. $\operatorname{Pd}(O A c)_{2}$ was used as the pre-catalyst along with (R)-BINAP as the chiral source. We successfully obtained a family of 3-phenyl-3-(aryl-amino)-indolin-2-one derivatives (11 in total) with excellent yields (up to 98\%) and enantioselectivities of up to $76 \%$ ee. The reaction is versatile and tolerant of a wide range of functional groups.

Key words oxindoles, intramolecular, bis(pinacolate)diboron, palladium, arylation, $\alpha$-ketimines

The oxindole framework, bearing a tetrasubstituted quaternary carbon stereocenter in the 3-position, is a privileged and common substructure found in numerous natural products and biologically active molecules. ${ }^{1}$ Our group has particular interest in the synthesis of 3-amino-2-oxindoles due to their presence in promising drug candidates, particularly for cancer and neurodegenerative diseases. ${ }^{2}$
Very recently we reported an interesting Rh-catalyzed addition of arylboronic acids to isatin-derived $\mathrm{N}$-Boc-protected ketimines to afford novel 3-amino-3-aryl-2-oxindoles in very good yields. Notably, this was the first catalytic enantioselective procedure with this substrate type. ${ }^{3}$ Although some methods have been described in the literature, ${ }^{4,5}$ we have investigated a novel one-pot borylation/intramolecular cyclization to give 3-amino-2-oxindoles. Although transition-metal-catalyzed ( $\mathrm{Rh}, \mathrm{Pd}$ ) arylation of protected ketimines using arylboron reagents is a well-established methodology for obtaining chiral amines, particularly tetrasubstituted quaternary centers; ${ }^{6}$ there has been very little reported on the intramolecular version. Besides our own report, the only other report is that of Ley and co-workers who disclosed an intramolecular arylation on a ketimine to afford oxindoles with an $\alpha$-tertiary amine at the 3-position. ${ }^{7}$ The methodology is interesting but limited to one type of ketimine substrate and also to one chiral phosphane ligand, namely $(R)$-DifluorPhos.

With our interest in this field, ${ }^{8}$ we decided to use our experience to develop a new efficient methodology to access enantiomerically pure 3-amino-2-oxindole derivatives 2 (Scheme 1).
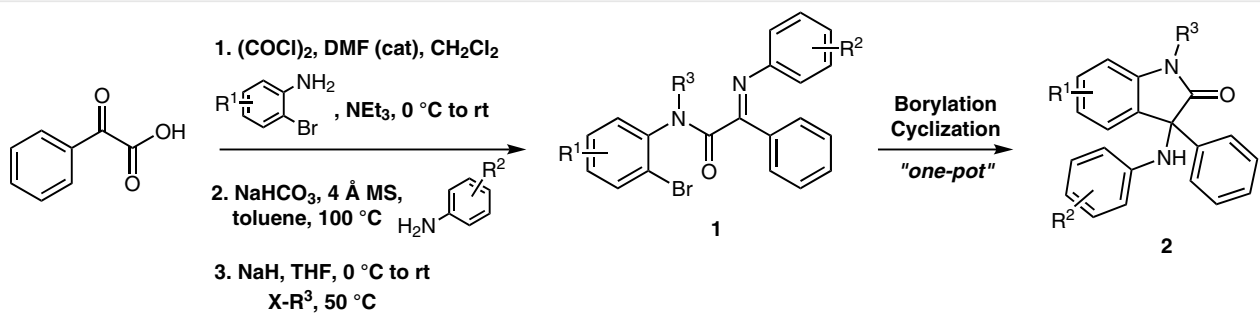

$\mathrm{X}-\mathrm{R}^{3}, 50^{\circ} \mathrm{C}$

Scheme 1 Intramolecular borylation/arylation of ortho-bromo- $\alpha$-ketimino amides 1 to give 3-amino-2-oxindoles 2 
ortho-Bromo- $\alpha$-ketimino amides $\mathbf{1}$ were synthesized according to the literature, ${ }^{7,9}$ from cheap and easily accessible phenylglyoxylic acid (Scheme 1). Our first approach was to borylate substrate 1a following the well-established conditions reported by Miyaura and co-workers, ${ }^{10 a}$ using bis(pinacolate)diboron $\left(\mathrm{B}_{2} \mathrm{Pin}_{2}\right)$ as the boron source, and 1,4-dioxane instead of dimethylsulfoxide (DMSO) as solvent. Gratifyingly we obtained the corresponding cyclic oxindole product $\mathbf{2 a}$ in $86 \%$ yield (Scheme 2 ) and presume that the boronic ester was formed in situ and then underwent cyclization.

We also tested the borylation conditions reported by Colobert and co-workers, ${ }^{10 \mathrm{~b}}$ using $\mathrm{Pd}(\mathrm{OAc})_{2}$ and DPEPhos ligand, pinacolborane (HBPin) and $\mathrm{NEt}_{3}$ as base, and the cyclic compound 2a was obtained in $64 \%$ yield, with only the presence of vestigial amounts of the borylated intermediate. We decided to study in depth this interesting reaction, where apparently the same Pd catalyst was able to catalyze the borylation of the $\mathrm{C}-\mathrm{Br}$ bond carbon and the cyclization<smiles>CN(C(=O)/C(=N/c1ccccc1)c1ccccc1)c1ccccc1Br</smiles>

1a

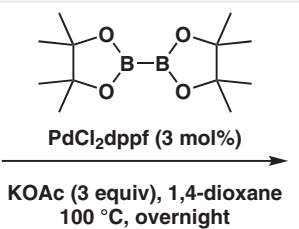

$100^{\circ} \mathrm{C}$, overnight

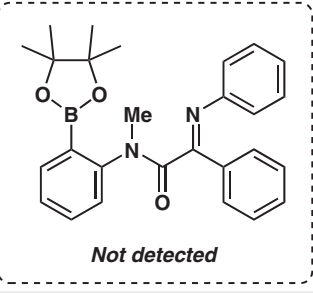

Scheme 2 One-pot borylation of 1 a to $2 a$

onto the $\mathrm{C}=\mathrm{N}$ unit. ${ }^{11}$ We then decided to optimize the reaction conditions and study the reaction scope. The results can be seen in Table 1 .

Table 1 Chiral Ligand Screening in the One-Pot Borylation/Intramolecular Arylation Reaction of Substrate $\mathbf{1 a}^{\mathrm{a}}$
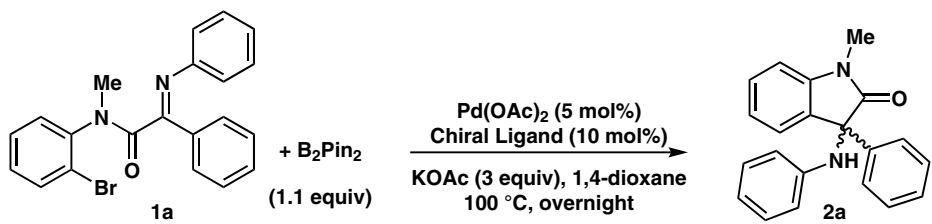

\begin{tabular}{|c|c|c|c|}
\hline Entry & Chiral ligand & Conversion (\%) & ee $(\%)^{b, c}$ \\
\hline 1 & (R)-BINAP & $>99$ & $68(S)$ \\
\hline 2 & $(R)$-Tol-BINAP & $>99$ & $37(S)$ \\
\hline 3 & $(R)$-SegPhos & 72 & $29(S)$ \\
\hline 4 & $(R, R)$-ChiraPhos & 83 & $18(S)$ \\
\hline 5 & (S)-iPr-MeOBIHEP & 99 & $15(R)$ \\
\hline 6 & $(S, S)-B D P P$ & 98 & $16(R)$ \\
\hline 7 & (R)-PhanePhos & 65 & $<10$ \\
\hline 8 & (R)-DifluorPhos & $>99$ & $23(S)$ \\
\hline 9 & (S)-JosiPhos & 67 & $<5$ \\
\hline 10 & JosPOPhos & 14 & $23(R)$ \\
\hline 11 & $(R, R, S, S)$-DuanPhos & 33 & $21(S)$ \\
\hline 12 & (R)-MonoPhos & $<10$ & $<5(S)$ \\
\hline 13 & (R)-Diox-MonoPhos & 93 & $58(R)$ \\
\hline 14 & $(R, R)(+)-\operatorname{Box}$ & 14 & $<10$ \\
\hline 15 & $(R)(+)-$ PyBox & $<10$ & $<10$ \\
\hline 16 & $(S, S)$-diene & $<10$ & $<5$ \\
\hline
\end{tabular}


Several chiral phosphane ligands were screened (Table 1, entries 1-11) and, in general, excellent to moderate conversions were achieved. Almost full conversion into 2a was obtained using BINAP ligands, ${ }^{12}(S)$-iPr-MeOBIHEP, $(S, S)-$ BDPP, and $(R)$-DifluorPhos ${ }^{7}$ (Table 1, entries 1, 2, 5, 6, and 8, respectively). Very low conversion was obtained with the phosphane-oxide ligand JosPOPhos (Table 1, entry 11). Phosphoramidite-type ligands ${ }^{13}$ were also screened (Table 1 , entries 12 and 13 ), but despite $(R)$-MonoPhos giving very poor results, the analogous phosphane ligand $(R)$-DioxMonoPhos gave much better results (Table 1, entry 13). We also screened bisoxazoline ligands ${ }^{14}$ (Table 1 , entries 14 and $15)$, but these were not very efficient. A chiral diene ligand $^{15}$ containing a bicyclo[2,2,2]octa-2,5-diene core gave the product in only trace quantities (Table 1, entry 16). Regarding the enantioselectivity, the best values were obtained using $(R)$-BINAP ligand (68\% ee, Table 1 , entry 1 ) and the phosphoramidite type $(R)$-Diox-MonoPhos (58\% ee, Table 1 , entry 13). An X-ray crystal-structure determination on compound $\mathbf{2} \mathbf{a}^{16}$ (see Supporting Information), showed that it had the $S$ absolute configuration, which is in agreement with the results of Ley's group ${ }^{7}$ for an analogous system. We decided to run further reaction screenings using $\mathrm{Pd}(\mathrm{OAc})_{2}$ and $(R)$-BINAP to optimize the conditions further. Boron reagent, base, and solvent were screened in this new one-pot borylation/intramolecular arylation reaction using substrate 1a. The results are shown in Table 2.

Table 2 Boron Reagent, Base and Solvent Screening in the One-Pot Borylation/Intramolecular Arylation of 1a

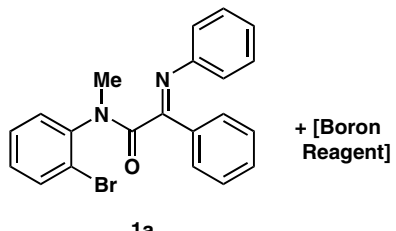

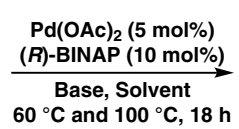

$1 \mathrm{a}$

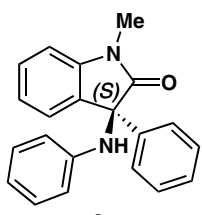

$2 \mathbf{a}$<smiles>c1ccc(-c2c(P(c3ccccc3)c3ccccc3)ccc3ccccc23)cc1</smiles>

(R)-BINAP

\begin{tabular}{|c|c|c|c|c|c|}
\hline Entry & Boron reagent & Base & Solvent & Conversion (\%) & ee $(\%)^{b}$ \\
\hline 1 & HBPin & KOAC & dioxane & 54 & 76 \\
\hline 2 & $\mathrm{~B}_{2}$ (cat) $)_{2}$ & KOAC & dioxane & 77 & 68 \\
\hline 3 & $\mathrm{~B}_{2}(\mathrm{npg})_{2}$ & KOAC & dioxane & 97 & 68 \\
\hline 4 & $\mathrm{~B}_{2}(\mathrm{OH})_{4}$ & KOAC & dioxane & 63 & 57 \\
\hline $5^{c}$ & HBPin & KOAC & dioxane & 99 & 60 \\
\hline 6 & $\mathrm{~B}_{2} \mathrm{Pin}_{2}$ & $\mathrm{Cs}_{2} \mathrm{CO}_{3}$ & dioxane & 90 & 47 \\
\hline 7 & $\mathrm{~B}_{2} \mathrm{Pin}_{2}$ & $\mathrm{NEt}_{3}$ & dioxane & $<10$ & 67 \\
\hline 8 & $\mathrm{~B}_{2} \mathrm{Pin}_{2}$ & $\mathrm{KOtBu}$ & dioxane & 99 & 30 \\
\hline 9 & $\mathrm{~B}_{2} \mathrm{Pin}_{2}$ & $\mathrm{~K}_{2} \mathrm{CO}_{3}$ & dioxane & 91 & 18 \\
\hline 10 & $\mathrm{~B}_{2} \mathrm{Pin}_{2}$ & $\mathrm{~K}_{3} \mathrm{PO}_{4}$ & dioxane & 87 & 15 \\
\hline 11 & $\mathrm{~B}_{2} \mathrm{Pin}_{2}$ & DIPEA & dioxane & 53 & 44 \\
\hline $12^{d}$ & $\mathrm{~B}_{2} \mathrm{Pin}_{2}$ & KOAC & $\mathrm{CH}_{2} \mathrm{Cl}_{2}$ & $<1$ & n.d. \\
\hline 13 & $\mathrm{~B}_{2} \mathrm{Pin}_{2}$ & KOAC & toluene & 86 & 36 \\
\hline 14 & $\mathrm{~B}_{2} \mathrm{Pin}_{2}$ & KOAC & $\mathrm{CH}_{3} \mathrm{CN}$ & 12 & 26 \\
\hline 15 & $\mathrm{~B}_{2} \mathrm{Pin}_{2}$ & KOAC & DME & 45 & 75 \\
\hline 16 & $\mathrm{~B}_{2} \mathrm{Pin}_{2}$ & KOAC & DCE & $<1$ & n.d.g \\
\hline 17 & $\mathrm{~B}_{2} \mathrm{Pin}_{2}$ & KOAC & THF & 19 & 38 \\
\hline $18^{\mathrm{d}, \mathrm{e}}$ & $\mathrm{B}_{2} \mathrm{Pin}_{2}$ & KOAC & $\mathrm{MeOH}$ & 31 & 10 \\
\hline $19^{d, f}$ & $\mathrm{~B}_{2} \mathrm{Pin}_{2}$ & KOAC & dioxane & 24 & 44 \\
\hline $20^{f}$ & $\mathrm{~B}_{2} \mathrm{Pin}_{2}$ & KOAC & toluene & 99 & 21 \\
\hline
\end{tabular}

${ }^{a}$ Reaction conditions: $\mathrm{Pd}(\mathrm{OAc})_{2}$ (5 mol\%), ( $R$ )-BINAP (10 mol\%), and solvent (1 mL) were stirred for 30 min at room temperature. After that, 1 a $(0.25 \mathrm{mmol})$, Boron reagent $(0.28 \mathrm{mmol})$, and base $(0.76 \mathrm{mmol})$ were added sequentially to the reaction vessel. Additional solvent $(1 \mathrm{~mL}) \mathrm{was}$ added and the reaction mixture stirred at $100{ }^{\circ} \mathrm{C}$ for $18 \mathrm{~h}$.

${ }^{b}$ Determined by chiral stationary phase HPLC (see Supporting Information for further details).

c Reaction run with $0.53 \mathrm{mmol}$ of HBPin.

d Reaction run at $60{ }^{\circ} \mathrm{C}$.

e $\mathrm{Pd}(\mathrm{OAC})_{2}$ and $(R)$-BINAP were pre-stirred in $\mathrm{CH}_{2} \mathrm{Cl}_{2}$.

${ }_{\mathrm{f}} \mathrm{Pd}(\mathrm{OAC})_{2}$ and $(R)$-BINAP were pre-stirred in DME.

g n.d. = not determined. 
As HBPin had already been shown to be successful in this reaction by Colobert and co-workers, ${ }^{10 \mathrm{~b}}$ we decided to test this boron reagent with the chiral $(R)$-BINAP ligand (Table 2, entries 1 and 5). Gratifyingly, we obtained a higher enantioselectivity (76\% ee, compared with 68\% using $\mathrm{B}_{2} \mathrm{Pin}_{2}$, compare Table 2 , entry 1 with Table 1 , entry 1 ), although the conversion was lower. We decided to increase the quantity of HBPin to 2.1 equivalents and almost full conversion of $\mathbf{2 a}$ was obtained, despite a slight decrease in ee (Table 2, entry 5). Other commercially available diboron reagents, such as arylboronate esters and acids, ${ }^{17}$ were also evaluated (Table 2, entries 2-4). We speculated that the steric bulk of the tetra(alkoxy)diboron reagent might play an important role in the reaction, but no significant alterations in conversion and enantioselectivity were noted when the less sterically hindered bis(neopentyl glycolato)diboron $\left(\mathrm{B}_{2}(\mathrm{npg})_{2}\right)$ was used (Table 2, entry 3 ). Less expensive tetrahydroxydiboron $\left(\mathrm{B}_{2}(\mathrm{OH})_{4}\right)$ was also tested, but lower conversions were achieved (Table 2, entry 4). The same happened with bis(catecholato)diboron $\left(\mathrm{B}_{2}(\mathrm{cat})_{2}\right)$. There was no change in the enantioselectivity but the conversion only reached a maximum of $77 \%$ (Table 2, entry 2 ). We decided to conduct a basescreening study, maintaining the other reagents, i.e., $\left(\mathrm{Pd}(\mathrm{OAC})_{2}\right.$ and $(R)$-BINAP) and $\mathrm{B}_{2} \mathrm{Pin}_{2}$ (Table 2, entries 6-11). Generally, organic bases such as $\mathrm{NEt}_{3}$ and $\mathrm{N}, \mathrm{N}$-diisopropylethylamine (DIPEA) are not the best choice for this reaction, since low conversions of 2a were obtained (Table 2, entries 7 and 11). High conversions were obtained with the inorganic bases $\mathrm{Cs}_{2} \mathrm{CO}_{3}, \mathrm{KOtBu}$, and $\mathrm{K}_{2} \mathrm{CO}_{3}$ (Table 2, entries 6, 8, and 9, respectively). Unfortunately, there was no improvement in the reaction enantioselectivity. Finally, we decided to evaluate the effect of the solvent (Table 2, entries 12-20). None of the desired product $\mathbf{2 a}$ was obtained using chlorinated solvents such as $\mathrm{CH}_{2} \mathrm{Cl}_{2}$ and 1,2-dichloroethane (DCE, Table 2, entries 12 and 16). We conducted the same reaction with $\mathrm{CH}_{2} \mathrm{Cl}_{2}$ in a sealed tube at $100{ }^{\circ} \mathrm{C}$ and again no product 2a was obtained. For good conversions, apolar aprotic solvents were the best. For example, toluene afforded the product with a conversion of $86 \%$ (Table 2 , entry 13 ), albeit with low enantioselectivity. However, upon using 1,2-dimethoxyethane (DME) as solvent, an enantioselectivity of $75 \%$ ee was obtained, despite a low conversion (Table 2, entry 15). So, we decided to use DME in the pre-complexation step between the $\mathrm{Pd}(\mathrm{OAc})_{2}$ and $(R)$ BINAP and then run the reaction in dioxane and toluene, after evaporation of the DME (Table 2, entries 19 and 20, respectively). No significant variations were observed in the conversions and enantioselectivities. At this point we established the following conditions to be the optimized conditions for this reaction: $\mathrm{Pd}(\mathrm{OAC})_{2}$ and $(R)$-BINAP as ligand, $\mathrm{B}_{2} \mathrm{Pin}_{2}$ as the boron source, KOAc as base, and dioxane as the solvent (see Table 1 , entry 1$).{ }^{18}$ The next step was to study the reaction scope and this study is shown in Scheme 3.

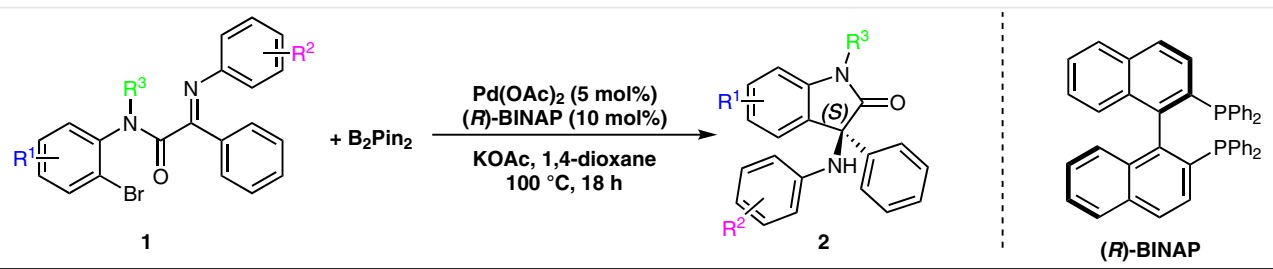

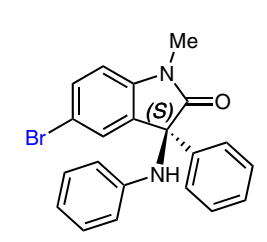

2b $43 \%$ isolated yield $10 \%$ ee

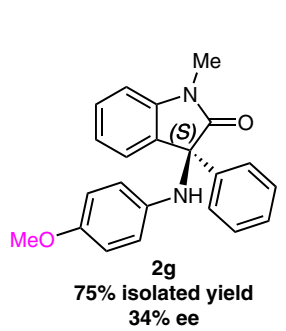
$34 \%$ ee<smiles>CN1C(=O)[C@@](Nc2ccccc2)(c2ccccc2)c2ccc(C(F)(F)F)cc21</smiles>
$2 c$ $98 \%$ isolated yield $22 \%$ ee

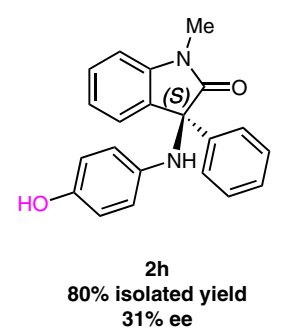<smiles>CN1C(=O)[C@@](Nc2ccccc2)(c2ccccc2)c2c(Cl)c(F)cc(Br)c21</smiles>

$0 \%$ isolated yield

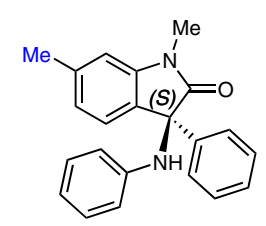

$2 i$ $91 \%$ isolated yield $43 \%$ ee<smiles>CN1C(=O)[C@@](Nc2ccccc2)(c2ccccc2)c2cc(Br)cc(Br)c21</smiles>

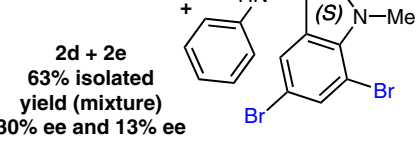<smiles>O=C1N(Cc2ccccc2)c2ccccc2[C@@]1(Nc1ccccc1)c1ccccc1</smiles><smiles>CN1C(=O)[C@@](Nc2ccccc2)(c2ccccc2)c2cc(C#N)ccc21</smiles><smiles>Cc1cc(C)c2c(c1)C(Nc1ccccc1)(c1ccccc1)C(=O)N2C</smiles>

Scheme 3 One-pot borylation/intramolecular asymmetric arylation reaction on ortho-bromo- $\alpha$-ketimino amide substrates $\mathbf{1 - k}$ affording 3-amino2-oxindoles 2-k 
In general, moderate to very good yields were obtained using substrates containing both electron-rich and electron-deficient substituents. The best yield was obtained with 1c - containing a $\mathrm{CF}_{3}$ electron-withdrawing group - to give 2c, in a yield of $98 \%$ (Scheme 3 ). The yield decreased slightly, when halogen substituents were present as the $\mathrm{R}^{1}$ substituent in the substrate (see, for example, compounds 2b,d,e). When several halogen substituents ( $C, F, B r)$ were present in the same ring no reaction occurred. We believe that in the borylation step, there is competition between these sites and the ortho- $\mathrm{Br}$ site for the boron unit. ${ }^{19}$ When we conducted the reaction with $\mathbf{1 e}$ it gave a mixture of $\mathbf{2 d}$ and $\mathbf{2 e}$, which would be expected (Scheme 3 ). Unfortunately, it was impossible to separate the two isomers by silica gel chromatography. Low enantioselectivities were observed for compounds $\mathbf{2 b}, \mathbf{d}, \mathbf{e}, \mathbf{i}, \mathbf{j}, \mathbf{k}$, the best being $43 \%$ ee ( $\mathbf{2} \mathbf{i}$, Scheme 3). Unfortunately, the only $\mathrm{R}^{2}$ substituents that we could introduce into the imine phenyl unit were the electron-donating 4-OMe and 4-OH groups (as in $\mathbf{1 g}$ and $\mathbf{1 h}$ ). However, gratifyingly both $\mathbf{2} \mathbf{g}$ and $\mathbf{2 h}$ were obtained in very good yields, despite giving low enantioselectivities (Scheme 3 ). In the case of functionalization of the amide (substituent $\mathrm{R}^{3}$ ) we could only manage to introduce a benzyl group as is the case for $\mathbf{1 f}$ (Scheme 3 ). The product 2c was obtained in high yield and low enantioselectivity ( $87 \%$ and $31 \%$ ee, respectively). Since the absolute configuration of $\mathbf{2 a}$ was determined, all of our products $\mathbf{2} \mathbf{b}$-k are expected to have the same $S$ configuration.

In conclusion, we have developed a catalytic approach to the synthesis of chiral 3-amino-2-oxindoles in high yields and good enantioselectivities using a hitherto unknown one-pot borylation/intramolecular asymmetric arylation sequence.

\section{Funding Information}

We are grateful for the award of a post-doctoral grant to C.S.M. (FRH/BPD/92394/2013) from the Fundação para a Ciência e a Tecnologia (FCT). The authors gratefully acknowledge Fundo Europeu de Desenvolvimento Regional (FEDER)-INALENTEJO for funding the program INMOLFARM - Molecular Innovation and Drug Discovery (ALENT-07-0224-FEDER-001743) and for financing the acquisition of the NMR equipment, project LADECA (ALENT-07-0262-FEDER001878). S.E.L. thanks University College Cork 2013 Research Fund and Science Foundation Ireland under grant no. 05/PICA/B802/EC07.

\section{Supporting Information}

Supporting information for this article is available online at https://doi.org/10.1055/s-0036-1590940.

\section{References and Notes}

(1) (a) Zhou, F.; Liu, Y.-L.; Zhou, J. Adv. Synth. Catal. 2010, 352, 1381. (b) Rudrangi, S. R. S.; Bontha, V. K.; Manda, V. R.; Bethi, S. Asian J. Res. Chem. 2011, 4, 335. (c) Trost, M.; Brennan, M. K. Synthesis 2009, 3003.

(2) For several examples, see: (a) Gal, C. S.-L.; Wagnon, J.; Simiand, J.; Griebel, G.; Lacour, C.; Guillon, G.; Barberis, C.; Brossard, G.; Soubrié, P.; Nisato, D.; Pascal, M.; Pruss, R.; Scatton, B.; Maffrand, J.-P.; Le Fur, G. J. Pharmacol. Exp. Ther. 2002, 300, 1122. (b) Ochi, M.; Kawasaki, K.; Kataoka, H.; Uchio, Y.; Nishi, H. Biochem. Biophys. Res. Commun. 2001, 283, 1118. (c) Ali, M. A.; Ismail, R.; Choon, T. S.; Yoon, Y. K.; Wei, A. C.; Pandian, S.; Kumar, R. S.; Osman, H.; Manogaran, E. Bioorg. Med. Chem. Lett. 2010, 20, 7064. (d) Rottmann, M.; McNamara, C.; Yeung, B. K. S.; Lee, M. C. S.; Zou, B.; Russell, B.; Seitz, P.; Plouffe, D. M.; Dharia, N. V.; Tan, J.; Cohen, S. B.; Spencer, R.; González-Páez, G. A.; Lakshminarayana, S. B.; Goh, A.; Suwanarusk, R.; Jegla, T.; Schmitt, E. K.; Beck, H.-P.; Brun, R.; Nosten, F.; Renia, L.; Dartois, V.; Keller, T. H.; Fidock, D. A.; Winzeler, E. A.; Diagana, T. T. Science 2010, 329, 1175.

(3) Marques, C. S.; Burke, A. J. Eur. J. Org. Chem. 2016, 806.

(4) For some examples, see: (a) Kaur, J.; Chimni, S. S.; Mahajan, S.; Kumar, A. RSC Adv. 2015, 5, 52481. (b) Lesma, G.; Landoni, N.; Pilati, T.; Sacchetti, A.; Silvani, A. J. Org. Chem. 2009, 74, 4537. (c) Shen, K.; Liu, X.; Lin, L.; Feng, X. Chem. Sci. 2012, 3, 327.

(5) (a) Kumagai, N.; Shibasaki, M. Bull. Chem. Soc.Jpn. 2015, 88, 503. (b) Burke, A. J. Tetrahedron Lett. 2016, 57, 1197.

(6) Catalytic Arylation Methods: From the Academic Lab to Industrial Processes; Burke, A. J.; Marques, C. S., Eds.; Wiley-VCH: Weinheim, 2015.

(7) Tolstoy, P.; Lee, S. X. Y.; Sparr, C.; Ley, S. V. Org. Lett. 2012, 14, 4810.

(8) (a) Marques, C. S.; Peixoto, D.; Burke, A. J. RSC Adv. 2015, 5, 20108. (b) Peixoto, D.; Viana, H.; Goth, A.; Marques, C. S.; Burke, A. J. WO 2015033261, 2015. (c) Marques, C. S.; Burke, A. J. ChemCatChem 2011, 3, 635. (d) Marques, C. S.; Burke, A. J. Tetrahedron 2013, 69, 10091. (e) Marques, C. S.; Locati, A.; Ramalho, J. P. P.; Burke, A. J. Tetrahedron 2015, 71, 3314. (f) Marques, C. S.; Burke, A. J. Tetrahedron: Asymmetry 2013, 24, 628. (g) Marques, C. S.; Dindaroglu, M.; Schmalz, H.-G.; Burke, A. J. RSC Adv. 2014, 4, 6035. (h) Marques, C. S.; Burke, A. J. Eur. J. Org. Chem. 2012, 4232. (i) Marques, C. S.; Burke, A. J. Eur. J. Org. Chem. 2010, 1639. (j) Marques, C. S.; Burke, A. J. Tetrahedron 2012, 68, 7211. (k) Marques, C. S.; Burke, A. J. ChemCatChem 2016, 8, 3518.

(9) Shin, I.; Ramgren, S. D.; Krische, M. J. Tetrahedron 2015, 71, 5776.

(10) (a) Ishiyama, T.; Murata, M.; Miyaura, N. J. Org. Chem. 1995, 60, 7508. (b) Broutin, P.-E.; Cÿerna, I.; Campaniello, M.; Leroux, F.; Colobert, F. Org. Lett. 2004, 6, 4419.

(11) For examples of arylation reactions in ketimines with boronic acids, see: (a) Jiang, C.; Lu, Y.; Hayashi, T. Angew. Chem. Int. Ed. 2014, 53, 9936. (b) Yang, G.; Zhang, W. Angew. Chem. Int. Ed. 2013, 52, 7540 .

(12) (a) Noyori, R.; Takaya, H. Acc. Chem. Res. 1990, 23, 345. (b) Akutagawa, S. Appl. Catal., A 1995, 128, 171.

(13) (a) Feringa, B. L. Acc. Chem. Res. 2000, 33, 346. (b) Teichert, J. F.; Feringa, B. L. Angew. Chem. Int. Ed. 2010, 49, 2486.

(14) Desimoni, G.; Faita, G.; Jørgensen, K. A. Chem. Rev. 2006, 106, 3561.

(15) (a) Glorius, F. Angew. Chem. Int. Ed. 2004, 43, 3364. (b) Shintani, R.; Hayashi, T. Aldrichimica Acta 2009, 42, 31. 
(16) CCDC 1571646 contains the supplementary crystallographic data for 2a. The data can be obtained free of charge from The Cambridge Crystallographic Data Centre via www.ccdc.cam.ac.uk/getstructures.

(17) For selected examples, see: (a) Fang, H.; Kaur, G.; Yan, J.; Wang, B. Tetrahedron Lett. 2005, 46, 1671. (b) Chow, W. K.; Yuen, O. Y.; Choy, P. Y.; So, C. M.; Lau, C. P.; Wong, W. T.; Kwong, F. Y. RSC Adv. 2013, 3, 12518. (c) Takaya, J.; Iwasawa, N. ACS Catal. 2012, 2, 1993. (d) Molander, G. A.; Trice, S. L. J.; Dreher, S. D. J. Am. Chem. Soc. 2010, 132, 17701.

(18) General Procedure for the Asymmetric Synthesis of Chiral 3Amino-2-oxindoles

In a Radley's ${ }^{\circledR} 12$ position carousel reactor under a nitrogen atmosphere was added $\mathrm{Pd}(\mathrm{OAc})_{2}(0.0125 \mathrm{mmol}, 5 \mathrm{~mol} \%)$, chiral ligand $(0.025 \mathrm{mmol}, 10 \mathrm{~mol} \%)$, and 1,4-dioxane $(1 \mathrm{~mL})$. The mixture was stirred for $30 \mathrm{~min}$ at room temperature, then the corresponding ortho-bromo- $\alpha$-ketimino amide substrate $\mathbf{1}$ (0.25 mmol), $\mathrm{B}_{2} \mathrm{Pin}_{2}$ ( $0.28 \mathrm{mmol}, 1.1$ equiv), KOAc ( $0.76 \mathrm{mmol}$ ), and 1,4-dioxane $(1 \mathrm{~mL})$ were added sequentially to the reaction vessel. The reaction was left stirring at $100{ }^{\circ} \mathrm{C}$ during $18 \mathrm{~h}$. After cooling to room temperature, the crude mixture was purified by silica gel chromatography using hexane/AcOEt (5:1) as eluent to afford the desired 3-phenyl-3-(aryl-amino)-indolin-2-one derivatives 2.

Compound 2a: Pale yellow solid; mp 86.2-87. ${ }^{\circ} \mathrm{C} .{ }^{1} \mathrm{H}$ NMR (400 $\left.\mathrm{MHz}, \mathrm{CDCl}_{3}\right) \delta=3.26\left(\mathrm{~s}, \mathrm{CH}_{3}, 3 \mathrm{H}\right), 6.34-6.36(\mathrm{~d}, \mathrm{Ar}, 2 \mathrm{H}, J=8 \mathrm{~Hz})$, 6.67-6.71 (t, Ar, $1 \mathrm{H}, J=8 \mathrm{~Hz}), 6.92-6.94(\mathrm{~d}, \mathrm{Ar}, 1 \mathrm{H}, J=8 \mathrm{~Hz})$, 6.98-7.02 (t, Ar, $2 \mathrm{H}, J=8 \mathrm{~Hz}), 7.08-7.12(\mathrm{t}, \mathrm{Ar}, 1 \mathrm{H}, J=8 \mathrm{~Hz})$, 7.33-7.42 (m, Ar, $5 \mathrm{H}), 7.55-7.57$ (d, Ar, $2 \mathrm{H}, J=8 \mathrm{~Hz}) .{ }^{13} \mathrm{C}$ NMR $\left(100 \mathrm{MHz}, \mathrm{CDCl}_{3}\right) \delta=26.80,68.08,108.90,115.54,119.40$, 123.32, 125.42, 126.73, 128.73, 129.07, 129.12, 129.51, 130.37, 140.19, 143.28, 145.09, 177.05. FTIR: 1499, 1722, 3055, 3373 $\mathrm{cm}^{-1}$. ESI-HRMS: $\mathrm{m} / z$ calcd for $\mathrm{C}_{21} \mathrm{H}_{18} \mathrm{~N}_{2} \mathrm{O}$ : 314.14191; found for $\mathrm{C}_{21} \mathrm{H}_{18} \mathrm{~N}_{2} \mathrm{ONa}$ : 337.13113 [ $\mathrm{M}^{+}+\mathrm{Na}$ ]. HPLC: Daicel Chiralpak IA column, $n$-hexane $/ i-\mathrm{PrOH}=90: 10,1.0 \mathrm{~mL} / \mathrm{min}, 220 \mathrm{~nm} ; t_{\mathrm{R}}=$ 32.447 min ( $R$, minor), 38.080 min ( $S$, major).

(19) Lam, K. C.; Marder, T. B.; Lin, Z. Organometallics 2010, 29, 1849. 